\title{
Epidemiology of traumatic brain injury in Austria
}

\author{
Walter Mauritz · Alexandra Brazinova · Marek Majdan · Johannes Leitgeb
}

Received: 15 June 2013 / Accepted: 16 October 2013 / Published online: 19 November 2013

(C) The Author(s) 2013. This article is published with open access at Springerlink.com

\section{Summary}

Background Traumatic brain injury (TBI) is an important cause of preventable deaths. The goal of this study was to provide data on epidemiology of TBI in Austria.

Methods Data on all hospital discharges, outpatients, and extra- as well as in-hospital deaths due to TBI were collected from various sources for the years 2009-2011. Population data (number of male/female people per agegroup, population of Austrian cities, towns, and villages) for 2009-2011 were collected from the national statistical office. Incidence, case fatality rate(s) (CFR), and mortality rate(s) (MR) were calculated for the whole population and for age groups.

Results Incidence (303/100,000/year), CFR (3.6\%), and MR (11/100,000/year) of TBI in Austria are comparable with those from other European countries. We found a high rate of geriatric TBI. The ratio between male and female cases was 1.4:1 for all cases, and was 2.2:1 for fatal cases. The most common mechanism was falls; traffic accidents accounted for only $7 \%$ of the cases. Males died more frequently from traffic accidents and suicides,

Assoc. Prof. W. Mauritz ( $\square)$

Anaesthesiology and Intensive Care Medicine,

Trauma Hospital “Lorenz Boehler", Donaueschingestrasse 13, 1200 Vienna, Austria

e-mail:walter.mauritz@auva.at

Assist. Prof. A. Brazinova · M. Majdan

Department of Public Health, Faculty of Health and Social Services,

Trnava University, Vienna, Austria

e-mail: abrazinova@igeh.org

M. Majdan

e-mail: mmajdan@igeh.org

Assist. Prof. J. Leitgeb

Department of Traumatology,

Medical University of Vienna, Vienna, Austria

e-mail: johannes.leitgeb@meduniwien.ac.at and females died more frequently from falls. CFRs and MRs increased with increasing age. CFRs were higher in patients from less populated areas, and MRs were lower in cases who lived closer to hospitals that admitted TBI.

Conclusions The high rate of geriatric TBI warrants better prevention of falls in this age group.

Keywords Traumatic brain injury · Epidemiology · Outcome $\cdot$ Severity $\cdot$ Age $\cdot$ Sex $\cdot$ Geographical factors

\section{Epidemiologie des Schädel-Hirn-Traumas in Österreich}

\section{Zusammenfassung}

Ziel der Studie Schädelhirntraumen (SHT) sind eine relevante Ursache von potentiell verhinderbaren Todesfällen. Das Ziel der Studie war, Daten zur Epidemiologie des SHT in Österreich zu erheben.

Methodik Angaben zu SHT-bedingten Spitalaufnahmen und Ambulanzbesuchen sowie zu präklinischen und innerklinischen Todesfällen für die Jahre 2009-2011 wurden von verschiedenen Institutionen zur Verfügung gestellt. Angaben zur Bevölkerung (Geschlechtsverteilung, Altersgruppen, Einwohnerzahlen der österreichischen Gemeinden) der Jahre 2009-2011wurden von der Webseite der „Statistik Austria“ heruntergeladen. Inzidenz, Letalität, und Mortalität wurden für die gesamte Population sowie für Altersgruppen errechnet.

Ergebnisse Inzidenz (303/100.000/Jahr), Letalität $(3,6 \%)$, und Mortalität (11/100.000/Jahr) des SHT in Österreich entsprechen den Werten, die für andere europäische Länder erhoben wurden. Auffällig war die hohe Anzahl von geriatrischen SHT-Fällen. Das Verhältnis zwischen männlichen und weiblichen Fällen betrug 1,4:1 insgesamt, und betrug 2,2:1 in Fällen mit letalem Ausgang. Der häufigste Unfallmechanismus war Fall/ Sturz; Verkehrsunfälle machten nur $7 \%$ der Fälle aus. 
Männer verstarben häufiger durch Verkehrsunfälle und Selbstmorde, Frauen verstarben häufiger durch Fall/ Sturz. Letalität und Mortalität nahmen mit zunehmendem Alter zu. Die Letalität war höher bei Patienten aus Regionen mit geringer Bevölkerungsdichte. In Regionen mit einem Krankenhaus, das SHT-Fälle versorgt, war die Mortalität niedriger als in Regionen ohne solches.

Schlussfolgerungen Die hohe Rate an SHT-Fällen durch Fall/Sturz bei geriatrischen Patienten legt nahe, dass hier Präventionsmaßnahmen dringend erforderlich sind.

Schlüsselwörter Trauma $\cdot$ Schädelhirntrauma $\cdot$ Epidemiologie · Altersgruppen · Geschlecht · Unfallmechanismus - Geografische Faktoren

\section{Introduction}

Traumatic brain injury (TBI) is a major cause of morbidity and mortality, and is the leading cause of death in people aged 15-45 years [1]. Tagliaferri et al. [2] reported that TBI accounted for the majority of trauma deaths in Europe. TBI has been called "the silent epidemic" [3] because the actual number of cases is rarely known, and because people as well as policy makers are frequently unaware of the serious consequences of TBI. Due to a number of factors (e.g., prevention policies, safer cars), the incidence of TBI is decreasing in developed countries [4]. However, the decline in TBI cases aged $<40$ years is accompanied by an increase in geriatric TBI cases.

Epidemiology data on TBI in Austria are not available. There are some estimates regarding cases of moderate and severe TBI [5], which have been based on rates of hospital admissions. The goal of this article is to describe the epidemiology of TBI in Austria.

\section{Methods}

Only Austrian residents were included in this analysis. In the Austrian system, almost all patients with head trauma (even those with small cuts or bruises) are seen at hospital emergency rooms; therefore, there was no need to obtain statistics on visits to physician's offices.

Statistik Austria (national statistics office) provided data on all deaths (years 2009-2011) due to International Classification of Diseases [10th revision (ICD10)] codes S01.0-S01.9, S02.0, S02.1, S02.7, S06.0-S06.9, T01.0, T02.0, T04.0, T06.0, T90.1, T90.2, or T90.4-T90.9, and provided data on all hospital discharges (years 2009-2011) with ICD-10 codes S06.0-S06.9, T68, or T07. Patients who were transferred to another hospital as well as re-admissions are included twice. Data on TBI severity were not available. Data on hospital discharges as well as fatalities included year and month of TBI, age, sex, and residency (postcode) of the cases, and cause of accident. Data on fatalities had additional information on mechanism of accident (ICD-10 codes V01.1-Y89.9) and location of death. Data on hospital discharges had additional information on duration of hospital stay and outcome (discharge or death). Data on the population of the area where the patients lived and on the availability of a hospital admitting TBI within the area of residency were added to the database. Statistik Austria provided data regarding the size of the age-groups (years 2009-2011; 5-year intervals) of the Austrian population.

Data on hospital discharges (years 2009-2011; ICD-10 codes S06.0-S06.9) to seven trauma centers funded by the Austrian Worker's Compensation Board (Allgemeine Unfallversicherungsanstalt, AUVA) were provided by the office of the Medical Director. These data were available with hospital ID numbers; thus, we were able to estimate the number of re-admissions (86/7,734 cases; $1.11 \%$ ) because these cases had identical hospital ID numbers. Data on outpatient treatment for TBI (years 2008-2010) were provided by AUVA; age, sex, number of outpatients, ICD-10 code (S06.0-S06.9), and name of hospital were available. During these 3 years, the trauma hospitals treated close to a million outpatients, and 1,483 of these were TBI cases. The total number of outpatients treated for TBI was estimated using data on annual trauma department visits from Statistik Austria, which, unfortunately, did not provide a diagnosis other than "injury." Data from the prospective data collection of the Trauma hospital "Lorenz Boehler" in Vienna were used to estimate the number of multiple trauma cases with TBI. TBI (= any Abbreviated Injury Score (AIS) for the region "head" >0) was present in $138 / 246$ cases $(43.9 \%$, years 2008-2011) that had been coded as "multiple trauma." The total number of multiple trauma cases with TBI was estimated using this factor.

Data on TBI discharges of Austrian residents to Austrian hospitals were provided by the office of the Main Association of the Austrian Social Security Institutions. This database had information on the number of interhospital transfers ( $n=3,880$ in 2009-2011) of TBI patients. These cases were identified in the database provided by Statistik Austria by searching for cases with identical age, sex, residency, trauma mechanism, and ICD-10 diagnosis, and double entries were marked as "transfers." A total of 3,150 cases were found.

All databases had complete sets of data for 3 years. Data for the 3 years from 2009 to 2011 were averaged for calculation of incidence (cases/100,000/year), case fatality rates (CFRs; deaths/number of cases), and mortality rates (MRs; deaths/100,000/year) by age-groups and sex. Data were not averaged for all other analyses. We investigated hospital discharges and causes of death (males vs. females), CFR and MR vs. cause and diagnosis of TBI, and CFR and MR vs. availability of a hospital admitting TBI in the residential area, and vs. population of residential area.

Means with respective standard deviations were used as central measures of continuous variables, and counts with percentages were used as frequency measures of categorical variables. For the statistical analysis for continuous variables, Student's $T$-test, and for the analysis of categorical variables, the $\chi^{2}$ test, was used. A $p$-value of $<0.05$ was considered statistically significant. 


\section{Results}

There were no differences in case numbers between the years 2009, 2010, and 2011; they contributed to 33.4, 33.3 , and $33.3 \%$ of all TBI cases, respectively. Overall incidence was 303/100,000/year (Table 1); this number included all hospital survivors, all patients who died, and all patients treated as outpatients (estimated). Correction for re-admissions (estimated) and patients with multiple trauma plus TBI (estimated) gave an incidence of 305/100,000/year. Overall CFR was $3.6 \%$, and overall MR was 11/100,000/year.

TBI was seen more frequently in males (Fig. 1). The highest numbers of cases were found in male teens and in female octogenarians. The high number of cases in the female geriatric population, however, did not translate into a higher incidence, as the female population aged $>65$ years is larger than the male population aged $>65$ years (see also Table 1). The high incidence in pediatric patients was not associated with a high number of fatal cases (Fig. 2)-CFRs were lower than those in all other age-groups (Table 1). The lowest incidences were seen in adults of both sexes, with lower rates for females. Incidence increased in geriatric patients to reach a maximum of 2,422/100,000/year in female, and of 2,991/100,000/ year in male patients aged $>94$ years. These cases also had the highest CFR as well as MR. In cases $<15$ years of age, females had higher CFRs and MRs; in older cases,

Table 1 Age, sex, incidences, case fatality rates, and mortality rates

\begin{tabular}{|c|c|c|c|c|c|c|c|c|c|c|c|c|c|c|c|c|c|c|}
\hline & A & A & $\mathbf{A}$ & $\mathbf{A}$ & A & A & $\mathbf{F}$ & $\mathbf{F}$ & $\mathbf{F}$ & $\mathbf{F}$ & $\mathbf{F}$ & $\mathbf{F}$ & $\mathbf{M}$ & $\mathbf{M}$ & $\mathbf{M}$ & $\mathbf{M}$ & $\mathbf{M}$ & M \\
\hline & 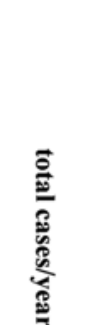 & 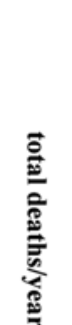 & 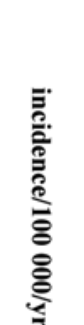 & 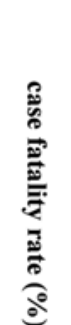 & 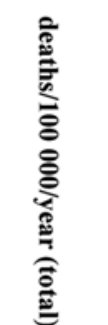 & 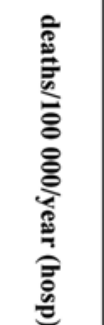 & 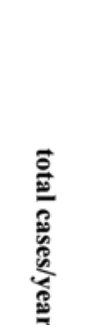 & 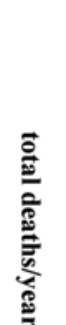 & 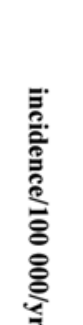 & 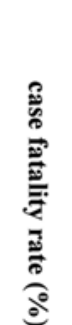 & 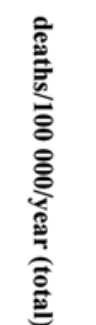 & 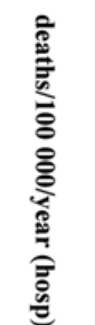 & 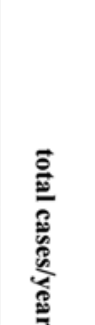 & 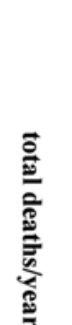 & 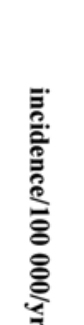 & 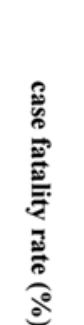 & 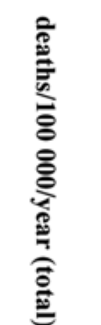 & 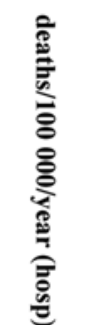 \\
\hline age & & & & & & & & & & & & & & & & & & \\
\hline $0-4$ & 1849 & 3 & 470 & 0.14 & 0.68 & 0.34 & 896 & 2 & 467 & 0.26 & 1.22 & 0.52 & 954 & 0 & 473 & 0.03 & 0.17 & 0.17 \\
\hline 5-9 & 1362 & 3 & 335 & 0.24 & 0.82 & 0.33 & 546 & 6 & 276 & 1.04 & 2.87 & 0.51 & 819 & 1 & 393 & 0.12 & 0.48 & 0.16 \\
\hline $10-14$ & 1534 & 11 & 348 & 0.72 & 2.50 & 0.23 & 534 & 1 & 248 & 0.25 & 0.62 & 0.31 & 992 & 1 & 439 & 0.13 & 0.59 & 0.15 \\
\hline $15-19$ & 2335 & 26 & 469 & 1.10 & 5.16 & 1.47 & 903 & 3 & 373 & 0.30 & 1.10 & 0.69 & 1423 & 14 & 558 & 1.01 & 5.62 & 2.22 \\
\hline $20-24$ & 1854 & 27 & 355 & 1.46 & 5.16 & 2.36 & 580 & 4 & 225 & 0.63 & 1.42 & 0.90 & 1277 & 27 & 483 & 2.14 & 10.33 & 3.78 \\
\hline $25-29$ & 1224 & 17 & 220 & 1.42 & 3.12 & 1.26 & 374 & 2 & 135 & 0.62 & 0.84 & 0.48 & 853 & 18 & 306 & 2.15 & 6.58 & 2.03 \\
\hline 30-34 & 905 & 22 & 170 & 2.43 & 4.13 & 1.06 & 270 & 2 & 102 & 0.86 & 0.88 & 0.13 & 630 & 14 & 235 & 2.28 & 5.35 & 1.99 \\
\hline $35-39$ & 893 & 26 & 150 & 2.87 & 4.32 & 1.23 & 275 & 2 & 92 & 0.85 & 0.78 & 0.33 & 615 & 20 & 208 & 3.31 & 6.88 & 2.14 \\
\hline 40-44 & 1044 & 41 & 149 & 3.93 & 5.87 & 1.00 & 324 & 4 & 93 & 1.34 & 1.25 & 0.58 & 703 & 19 & 200 & 2.75 & 5.49 & 1.42 \\
\hline $45-49$ & 1186 & 41 & 169 & 3.43 & 5.79 & 1.71 & 392 & 6 & 113 & 1.61 & 1.82 & 0.96 & 795 & 36 & 224 & 4.53 & 10.15 & 2.44 \\
\hline 50-54 & 1195 & 41 & 198 & 3.46 & 6.85 & 2.60 & 412 & 11 & 136 & 2.67 & 3.63 & 1.76 & 789 & 37 & 262 & 4.65 & 12.19 & 3.43 \\
\hline $55-59$ & 1010 & 18 & 202 & 1.75 & 3.53 & 3.26 & 363 & 6 & 142 & 1.65 & 2.35 & 1.57 & 666 & 31 & 272 & 4.70 & 12.78 & 5.03 \\
\hline $60-64$ & 994 & 58 & 214 & 5.87 & 12.57 & 5.89 & 315 & 9 & 131 & 2.75 & 3.61 & 2.08 & 677 & 48 & 302 & 7.04 & 21.27 & 9.96 \\
\hline $65-69$ & 1135 & 68 & 256 & 5.96 & 15.28 & 7.08 & 393 & 12 & 168 & 3.05 & 5.11 & 3.12 & 738 & 52 & 355 & 7.09 & 25.16 & 11.54 \\
\hline 70-74 & 1311 & 87 & 362 & 6.64 & 24.06 & 13.00 & 517 & 25 & 263 & 4.84 & 12.71 & 8.47 & 790 & 58 & 479 & 7.38 & 35.38 & 18.40 \\
\hline 75-79 & 1267 & 97 & 473 & 7.63 & 36.10 & 19.67 & 602 & 30 & 387 & 5.04 & 19.52 & 12.02 & 661 & 62 & 588 & 9.38 & 55.14 & 30.24 \\
\hline $80-84$ & 1571 & 127 & 721 & 8.06 & 58.15 & 39.64 & 881 & 56 & 638 & 6.32 & 40.33 & 28.98 & 685 & 65 & 859 & 9.54 & 81.90 & 58.08 \\
\hline $85-89$ & 1679 & 131 & 1213 & 7.82 & 94.87 & 71.76 & 1150 & 68 & 1143 & 5.94 & 67.92 & 54.00 & 525 & 59 & 1389 & 11.23 & 156.00 & 118.99 \\
\hline 90-94 & 822 & 62 & 2210 & 7.58 & 167.49 & 140.62 & 597 & 39 & 2096 & 6.48 & 135.82 & 119.43 & 225 & 23 & 2576 & 10.36 & 266.78 & 209.61 \\
\hline $95+$ & 286 & 21 & 2538 & 7.45 & 189.11 & 135.92 & 220 & 14 & 2422 & 6.20 & 150.24 & 98.94 & 65 & 7 & 2991 & 10.71 & 320.42 & 289.90 \\
\hline total & 25456 & 927 & 303 & 3.64 & 11.04 & 6.03 & 10544 & 303 & 245 & 2.87 & 7.04 & 4.86 & 14884 & 596 & 364 & 4.00 & 14.57 & 7.26 \\
\hline
\end{tabular}

$\mathrm{A}=$ all patients; $\mathrm{F}=$ female patients; $\mathrm{M}=$ male patients; hosp $=$ hospital; bold print: $\mathrm{p}<0.001$ for differences between male and female cases 


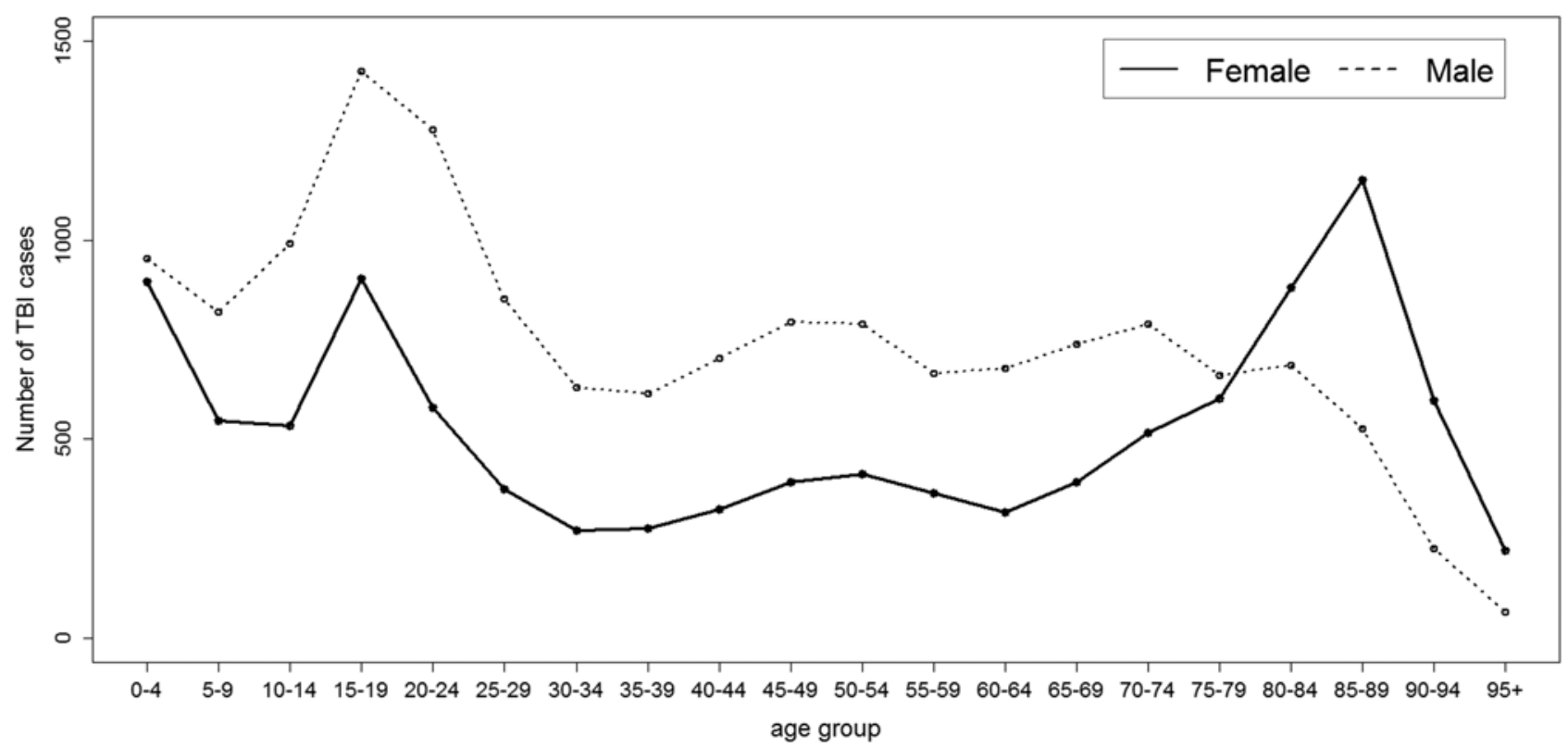

Fig. 1 Total cases of traumatic brain injury vs. age-groups and sex (1-year average)

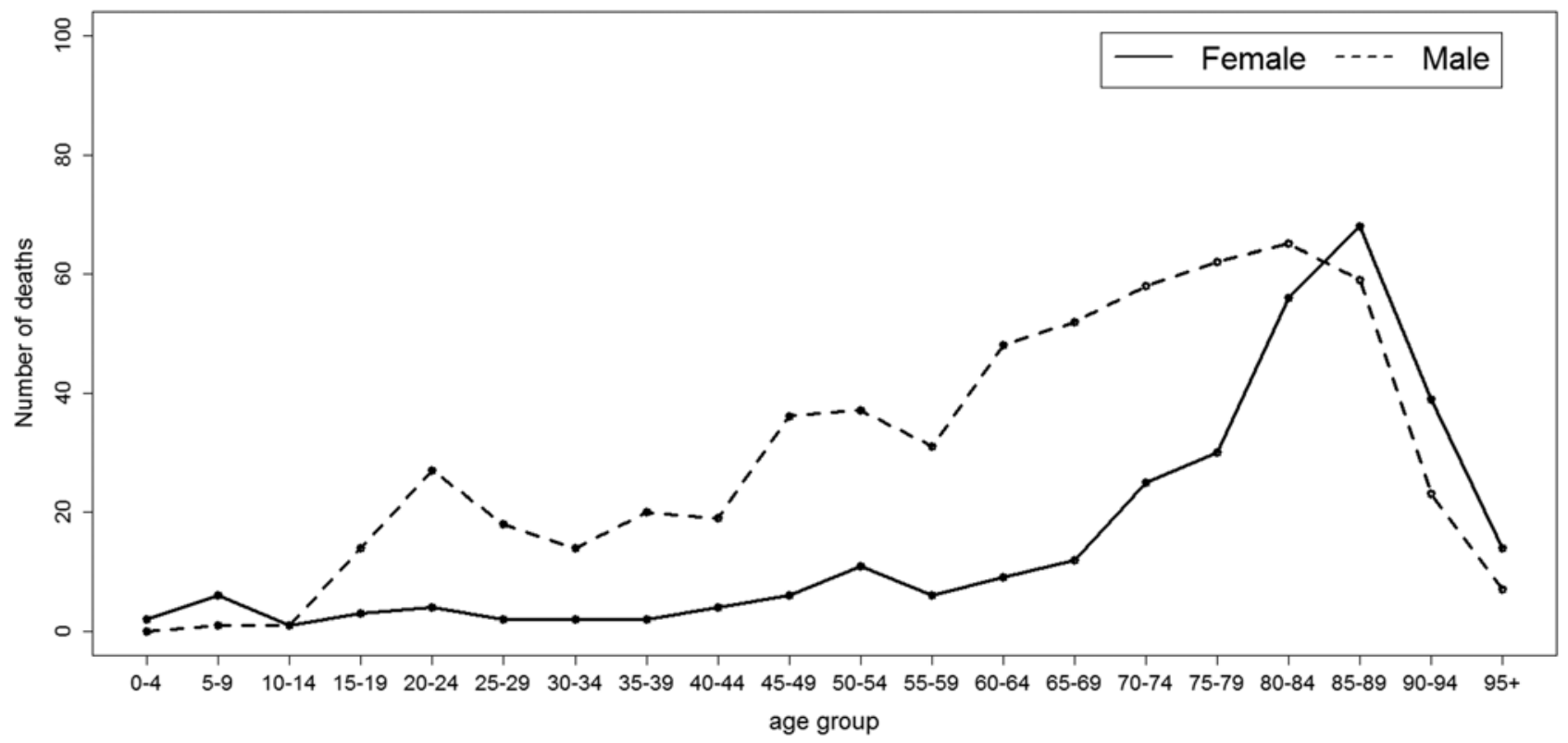

Fig. 2 Fatal cases of traumatic brain injury vs. age-groups and sex (1-year average)

males had significantly higher CFRs and MRs. The rates of extra-hospital deaths were $>50 \%$ for the pediatric and adult cases of both sexes, and decreased to approximately $30 \%$ in geriatric cases.

The proportion of different ICD-10 codes showed significant variations between the age-groups. The proportion of the most common diagnosis "concussion" decreased from approximately $90 \%$ to approximately $60 \%$ with increasing age. The proportions of "focal brain injury" (0.1-3.4\%), "subdural hematoma" (0.5-18.5\%), "subarachnoid hemorrhage" (0.2-7.2\%), and "other brain injury" (0.1-2.2\%) increased with increasing age.
The highest proportions of "brain edema" (0.7\%) and "epidural hematoma" (2.9\%) were found in cases aged 30-60 years, and were lower in younger as well as older patients. The proportions of "TBI with prolonged coma" (approximately $0.2 \%$ ) and "unspecified brain injury" (approximately 5\%) remained more or less constant over all age-groups.

With regard to hospital discharges (Table 2), approximately $58 \%$ of the cases were male. The mean age of females was 9 years higher than that of males. The cases were distributed evenly over the year. Injuries during private activities (mostly falls) were the most frequently 
original article

Table 2 Hospital discharges (January 2009 to December 2011)

\begin{tabular}{|c|c|c|c|c|c|c|c|}
\hline \multirow[b]{2}{*}{ Cases } & \multicolumn{2}{|l|}{ Female } & \multicolumn{2}{|l|}{ Male } & \multicolumn{2}{|l|}{ Total } & \multirow[t]{2}{*}{$p$-value } \\
\hline & $n$ & Percentage & $n$ & Percentage & $n$ & Percentage & \\
\hline & 30,790 & 41.8 & 42,832 & 58.2 & 73,622 & 100 & \\
\hline \multirow[t]{2}{*}{ Age } & Mean & $S D$ & Mean & $S D$ & Mean & $S D$ & \multirow[t]{2}{*}{$<0.001$} \\
\hline & 49.5 & 31.7 & 40.9 & 26.7 & 44.5 & 29.2 & \\
\hline Season & $n$ & Percentage & $n$ & Percentage & $n$ & Percentage & \multirow[t]{6}{*}{$<0.01$} \\
\hline Spring & 7,824 & 25.4 & 10,899 & 25.4 & 18,723 & 25.4 & \\
\hline Summer & 7,408 & 24.1 & 10,718 & 25.0 & 18,126 & 24.6 & \\
\hline Fall & 7,396 & 24.0 & 10,341 & 24.1 & 17,737 & 24.1 & \\
\hline Winter & 8,162 & 26.5 & 10,874 & 25.4 & 19,036 & 25.9 & \\
\hline Total & 30,790 & 100 & 42,832 & 100 & 73,622 & 100 & \\
\hline Cause & $n$ & Percentage & $n$ & Percentage & $n$ & Percentage & \multirow[t]{11}{*}{$<0.001$} \\
\hline Other private & 16,570 & 53.8 & 20,741 & 48.4 & 37,311 & 50.7 & \\
\hline Other/unknown & 9,715 & 31.6 & 13,053 & 30.5 & 22,768 & 30.9 & \\
\hline Traffic-related & 1,954 & 6.3 & 3,084 & 7.2 & 5,038 & 6.8 & \\
\hline Sports-related & 1,345 & 4.4 & 2,625 & 6.1 & 3,970 & 5.4 & \\
\hline Work-related & 481 & 1.6 & 1,508 & 3.5 & 1,989 & 2.7 & \\
\hline Violence-related & 272 & 0.9 & 1,066 & 2.5 & 1,338 & 1.8 & \\
\hline School-related & 343 & 1.1 & 533 & 1.2 & 876 & 1.2 & \\
\hline Home/garden work & 100 & 0.3 & 181 & 0.4 & 281 & 0.4 & \\
\hline Suicide attempt & 10 & 0.0 & 41 & 0.1 & 51 & 0.1 & \\
\hline Total & 30,790 & 100 & 42,832 & 100 & 73,622 & 100 & \\
\hline Diagnosis & $n$ & Percentage & $n$ & Percentage & $n$ & Percentage & \multirow[t]{12}{*}{$<0.001$} \\
\hline Concussion & 24,022 & 78.0 & 32,641 & 76.2 & 56,663 & 77.0 & \\
\hline Subdural hematoma & 2,138 & 6.9 & 2,995 & 7.0 & 5,133 & 7.0 & \\
\hline Unspecified brain injury & 1,383 & 4.5 & 2,067 & 4.8 & 3,450 & 4.7 & \\
\hline Diffuse brain injury & 956 & 3.1 & 1,630 & 3.8 & 2,586 & 3.5 & \\
\hline Subarachnoid hemorrhage & 998 & 3.2 & 1,294 & 3.0 & 2,292 & 3.1 & \\
\hline Focal brain injury & 513 & 1.7 & 834 & 1.9 & 1,347 & 1.8 & \\
\hline Epidural hematoma & 374 & 1.2 & 693 & 1.6 & 1,067 & 1.4 & \\
\hline Other brain injury & 311 & 1.0 & 519 & 1.2 & 830 & 1.1 & \\
\hline Brain edema & 73 & 0.2 & 124 & 0.3 & 197 & 0.3 & \\
\hline Injury with prolonged coma & 22 & 0.1 & 35 & 0.1 & 57 & 0.1 & \\
\hline Total & 30,790 & 100 & 42,832 & 100 & 73,622 & 100 & \\
\hline Hospital days & $n$ & Percentage & $n$ & Percentage & $n$ & Percentage & \multirow[t]{10}{*}{$<0.001$} \\
\hline$<1$ & 1,926 & 6.3 & 4,253 & 9.9 & 6,179 & 8.4 & \\
\hline $1-3$ & 21,522 & 69.9 & 28,606 & 66.8 & 50,128 & 68.1 & \\
\hline $4-7$ & 3,218 & 10.5 & 3,627 & 8.5 & 6,845 & 9.3 & \\
\hline $8-14$ & 2,044 & 6.6 & 2,751 & 6.4 & 4,795 & 6.5 & \\
\hline $15-21$ & 844 & 2.7 & 1,239 & 2.9 & 2,083 & 2.8 & \\
\hline $22-28$ & 569 & 1.8 & 927 & 2.2 & 1,496 & 2.0 & \\
\hline 29-35 & 219 & 0.7 & 389 & 0.9 & 608 & 0.8 & \\
\hline $35+$ & 448 & 1.5 & 1,040 & 2.4 & 1,488 & 2.0 & \\
\hline Total & 30,790 & 100 & 42,832 & 100 & 73,622 & 100 & \\
\hline Outcome & $n$ & Percentage & $n$ & Percentage & $n$ & Percentage & \multirow[t]{4}{*}{0.699} \\
\hline Died & 627 & 2.0 & 891 & 2.1 & 1,518 & 2.1 & \\
\hline Discharged & 30,163 & 98.0 & 41,941 & 97.9 & 72,104 & 97.9 & \\
\hline Total & 30,790 & 100 & 42,832 & 100 & 73,622 & 100 & \\
\hline
\end{tabular}


Table 2 (continued)

\begin{tabular}{|l|l|l|l|l|l|l|l|}
\hline & Female & \multicolumn{3}{c}{ Male } & Total & \multicolumn{2}{c|}{$p$-value } \\
\hline Age & Mean & SD & Mean & SD & Mean & $S D$ & \\
\hline Died & 78.4 & 17.3 & 69.2 & 20.0 & 73.0 & 19.5 & $<0.001$ \\
\hline Discharged & 48.9 & 31.6 & 40.3 & 26.5 & 43.9 & 29.0 & $<0.001$ \\
\hline Total & 49.5 & 31.7 & 40.9 & 26.7 & 44.5 & 29.2 & $<0.001$ \\
\hline
\end{tabular}

The $p$-value relates to the differences between females and males $S D$ standard deviation

observed cause, followed by traffic accidents that contributed to $7 \%$ of the cases. Three-quarter of the cases were diagnosed as "concussion," $7 \%$ had "subdural hematoma," and 3\% each had "subarachnoid hemorrhage" or "diffuse brain injury." "Epidural hematoma" as well as "focal brain lesions" were diagnosed in $<2 \%$ of the cases.

Two-third $(62.3 \%)$ of the 719 cases/year treated as outpatients were male. The mean age of male $(35.8 \pm 19.8$ years) as well as female cases (38.6 \pm 23.2 years) was significantly lower than that of admitted cases. Most cases $(91.3 \%)$ were diagnosed as "concussion"; intracranial hematomas were diagnosed in only $4.8 \%$. Few cases $(0.9 \%)$ were observed for some hours in the emergency room, $3.1 \%$ received medications, and all others just received medical advice. The number of patients who left against medical advice has not been recorded.

Between 2009 and 2011, 8,435 trauma-related deaths had been registered; of these, 2,665 (31.6\%) were due to TBI. More than two-third of the patients were male, and their mean age was almost 10 years lower than that of females (Table 3 ). The cases were distributed evenly over the seasons. Three-quarter of the deaths were due to accidents, and these were significantly more frequent in females. The most important mechanisms of accidents were "falls" followed by "other factors" (e.g., banging the head against an object, etc.) and "traffic-related" injuries. Suicides were the second most important cause; these were seen significantly more frequently in males (25 vs. $5 \%$ of all deaths). The most important mechanisms of suicides were gunshots to the head. With regard to the location of TBI, most cases happened at "other locations" (e.g., outdoors, at homes of friends or relatives, etc) followed by "home" and "street." The cases where location was "unknown" are those who died from sequelae of TBI. Most patients died at hospitals; approximately a quarter of them died at home; some died at "other locations" (e.g., the scene of TBI); and a few died at other medical institutions. Significant differences between patients who died from accidents and those who died from suicides were found: most accidental cases were admitted to hospitals, and fewer died on the scene of TBI, whereas suicide cases mostly died at the scene of TBI, and only few of these survived until hospital admission.

An analysis of CFRs (based on hospital discharges) for different causes of TBI and for different diagnoses is given in Table 4. Cases of TBI due to "school" accidents, to "sports," or to "inter-personal violence" had CFRs $<1 \%$. Most other causes had CFRs between 1 and
$5 \%$. Attempted suicide was found to have the highest CFR; half of the patients who reached the hospital alive died there. Cases of "concussion" had the lowest CFR; "epidural hematoma" had a CFR of $3.7 \%$; "diffuse brain injury" and "subarachnoid hemorrhage" had a CFR of approximately $7 \%$, "subdural hematoma" had a CFR of $11.6 \%$; and "brain edema" had the highest CFR of $33.5 \%$.

The size of the village/town/city where the TBI cases lived had significant influence on CFRs and MRs-both decreased significantly with increasing population (Table 5). Incidence decreased as well (statistically insignificant). The availability of a hospital that admitted TBI cases in the area of residency had a small (statistically insignificant) effect on CFRs. However, if only TBI cases that happened at home are considered, MR was significantly lower in cases that happened closer to hospitals (2.29 vs. 3.34 deaths $/ 100,000 /$ year, $p<0.001)$. It seems that most cases were treated at hospitals in their country of residence; the proportion of TBI cases in each province closely matched the proportion of TBI hospital discharges in that province.

\section{Discussion}

Austria is a small Central European country $\left(83,855 \mathrm{~km}^{2}\right.$, 32,377 square miles) with nine provinces. It is populated by approximately 8.4 million residents. Only one-third of the country lies $<500 \mathrm{~m}(1,640 \mathrm{ft})$; three-quarters are covered by the Eastern Alps and their foothills. Approximately a quarter of the population lives in the capital area (Vienna and suburbs), another quarter lives in 120 cities with $>7,500$ inhabitants (mostly in flat and/or low-lying areas), and the other $50 \%$ live in 2,236 towns and villages with $<7,500$ inhabitants (approximately half of these in the Alpine area). Approximately half of the population lives close to one of the 84 hospitals that admit TBI cases. Despite excellent cover by air medical services (38 helicopters) and ambulance cars, prehospital time (including treatment by emergency physicians) can exceed $90 \mathrm{~min}$ in some difficult-to-reach areas. These conditions are the reason why the CFR was higher in less populated areas, and why hospital mortality was lower in cases who lived closer to a hospital admitting TBI cases. A comparable finding was published in a study from the United States [6]: the CFR tended to decrease with an increase in population density (with the notable exception of the District of Columbia). 
original article

Table 3 Fatal traumatic brain injury cases in Austrian residents (January 2009 to December 2011)

\begin{tabular}{|c|c|c|c|c|c|c|c|}
\hline \multirow[b]{2}{*}{ Cases } & \multicolumn{2}{|c|}{ Female } & \multicolumn{2}{|l|}{ Male } & \multicolumn{2}{|l|}{ Total } & \multirow[t]{2}{*}{$p$-value } \\
\hline & $n$ & Percentage & $n$ & Percentage & $n$ & Percentage & \\
\hline & 825 & 30.9 & 1,840 & 69.0 & 2,665 & 100 & \\
\hline \multirow[t]{2}{*}{ Age } & Mean & $S D$ & Mean & $S D$ & Mean & $S D$ & \\
\hline & 73.5 & 19.8 & 62.5 & 20.2 & 65.9 & 20.7 & $<0.001$ \\
\hline Season & $n$ & Percentage & $n$ & Percentage & $n$ & Percentage & \multirow[t]{6}{*}{0.571} \\
\hline Fall & 205 & 24.9 & 462 & 25.1 & 667 & 25.0 & \\
\hline Spring & 188 & 22.8 & 456 & 24.8 & 644 & 24.2 & \\
\hline Summer & 212 & 25.7 & 471 & 25.6 & 683 & 25.6 & \\
\hline Winter & 220 & 26.7 & 451 & 24.5 & 671 & 25.2 & \\
\hline Total & 825 & 100 & 1,840 & 100 & 2,665 & 100 & \\
\hline Cause & $n$ & Percentage & $n$ & Percentage & $n$ & Percentage & \multirow[t]{8}{*}{$<0.001$} \\
\hline Accident & 731 & 88.6 & 1.266 & 68.8 & 1.997 & 74.9 & \\
\hline Suicide & 41 & 4.9 & 467 & 25.4 & 508 & 19.1 & \\
\hline Sequelae of TBI & 20 & 2.4 & 66 & 3.6 & 86 & 3.2 & \\
\hline Not defined (accident or suicide) & 9 & 1.1 & 28 & 1.5 & 37 & 1.4 & \\
\hline Aggression & 23 & 2.8 & 12 & 0.7 & 35 & 1.3 & \\
\hline latrogen & 1 & 0.1 & 1 & 0.1 & 2 & 0.1 & \\
\hline Total & 825 & 100 & 1,840 & 100 & 2,665 & 100 & \\
\hline Mechanism of accidents & $n$ & Percentage & $n$ & Percentage & $n$ & Percentage & \multirow[t]{9}{*}{$<0.001$} \\
\hline Fall & 473 & 64.7 & 620 & 48.9 & 1,093 & 54.7 & \\
\hline Other factor & 158 & 21.6 & 361 & 28.5 & 519 & 26.0 & \\
\hline Traffic-related & 90 & 12.3 & 232 & 18.3 & 322 & 16.1 & \\
\hline Accidental hit & 4 & 0.6 & 23 & 1.8 & 27 & 1.4 & \\
\hline Work-related & 1 & 0.1 & 15 & 1.2 & 16 & 0.8 & \\
\hline Sports-related & 1 & 0.1 & 10 & 0.8 & 11 & 0.6 & \\
\hline Trapped by object(s) & 0 & 0.0 & 5 & 0.4 & 5 & 0.3 & \\
\hline Total & 731 & 100 & 1,266 & 100 & 1,997 & 100 & \\
\hline Mechanism of suicides & $n$ & Percentage & $n$ & Percentage & $n$ & Percentage & \multirow[t]{6}{*}{$<0.001$} \\
\hline Fall & 20 & 48.8 & 26 & 5.6 & 46 & 9.1 & \\
\hline Gun & 19 & 46.3 & 422 & 90.4 & 441 & 86.8 & \\
\hline Vehicle/train & 2 & 4.9 & 15 & 3.2 & 17 & 3.3 & \\
\hline Other mechanism & 0 & 0.0 & 4 & 0.9 & 4 & 0.8 & \\
\hline Total & 41 & 100 & 467 & 100 & 508 & 100 & \\
\hline Location of TBI & $n$ & Percentage & $n$ & Percentage & $n$ & Percentage & \multirow[t]{12}{*}{$<0.001$} \\
\hline Other & 448 & 54.3 & 929 & 50.5 & 1,377 & 51.7 & \\
\hline Home & 223 & 27.0 & 495 & 26.9 & 718 & 26.9 & \\
\hline Street & 94 & 11.4 & 248 & 13.5 & 342 & 12.8 & \\
\hline Unknown & 18 & 2.2 & 63 & 3.4 & 81 & 3.0 & \\
\hline Care center & 30 & 3.6 & 29 & 1.6 & 59 & 2.2 & \\
\hline Workplace & 5 & 0.6 & 25 & 1.4 & 30 & 1.1 & \\
\hline Mountain & 2 & 0.2 & 23 & 1.3 & 25 & 0.9 & \\
\hline Railway & 2 & 0.2 & 17 & 0.9 & 19 & 0.7 & \\
\hline Sports facility & 2 & 0.2 & 10 & 0.5 & 12 & 0.5 & \\
\hline Hospital & 1 & 0.1 & 1 & 0.1 & 2 & 0.1 & \\
\hline Total & 825 & 100 & 1,840 & 100 & 2,665 & 100 & \\
\hline
\end{tabular}


Table 3 (continued)

\begin{tabular}{|c|c|c|c|c|c|c|c|}
\hline \multirow[b]{2}{*}{ Location of death (all causes) } & \multicolumn{2}{|c|}{ Female } & \multicolumn{2}{|l|}{ Male } & \multicolumn{2}{|l|}{ Total } & \multirow{2}{*}{$\begin{array}{l}p \text {-value } \\
<0.001\end{array}$} \\
\hline & $n$ & Percentage & $n$ & Percentage & $n$ & Percentage & \\
\hline Hospital & 544 & 65.9 & 859 & 46.7 & 1,403 & 52.6 & \\
\hline Home & 155 & 18.8 & 498 & 27.1 & 653 & 24.5 & \\
\hline Other & 69 & 8.4 & 395 & 21.5 & 464 & 17.4 & \\
\hline Other medical institution & 55 & 6.7 & 85 & 4.6 & 140 & 5.3 & \\
\hline Transport & 2 & 0.2 & 3 & 0.2 & 5 & 0.2 & \\
\hline Total & 825 & 100 & 1,840 & 100 & 2,665 & 100 & \\
\hline Location of death (accidents) & $n$ & Percentage & $n$ & Percentage & $n$ & Percentage & $<0.001$ \\
\hline Hospital & 524 & 71.7 & 758 & 59.9 & 1,282 & 64.2 & \\
\hline Home & 110 & 15.0 & 197 & 15.6 & 307 & 15.4 & \\
\hline Other & 48 & 6.6 & 249 & 19.7 & 297 & 14.9 & \\
\hline Care center & 47 & 6.4 & 60 & 4.7 & 107 & 5.4 & \\
\hline Transport & 2 & 0.3 & 2 & 0.2 & 4 & 0.2 & \\
\hline Total & 731 & 100 & 1,266 & 100 & 1,997 & 100 & \\
\hline Location of death (suicides) & $n$ & Percentage & $n$ & Percentage & $n$ & Percentage & 0.043 \\
\hline Home & 21 & 51.2 & 273 & 58.5 & 294 & 57.9 & \\
\hline Other & 11 & 26.8 & 127 & 27.2 & 138 & 27.2 & \\
\hline Hospital & 6 & 14.6 & 61 & 13.1 & 67 & 13.2 & \\
\hline Care center & 3 & 7.3 & 5 & 1.1 & 8 & 1.6 & \\
\hline Transport & 0 & 0.0 & 1 & 0.2 & 1 & 0.2 & \\
\hline Total & 41 & 100 & 467 & 100 & 508 & 100 & \\
\hline
\end{tabular}

Table 4 Case fatality rates of hospital discharges for different causes and diagnoses

The CFR values are significantly different $(p<0.001)$ $C F R$ case fatality rate

\begin{tabular}{|c|c|c|c|c|}
\hline & $\operatorname{Died}(n)$ & Discharged $(n)$ & Total $(n)$ & CFR (\%) \\
\hline \multicolumn{5}{|l|}{ Cause } \\
\hline School & 1 & 875 & 876 & 0.1 \\
\hline Sports-related & 9 & 3,961 & 3,970 & 0.2 \\
\hline Violence & 4 & 1,334 & 1,338 & 0.3 \\
\hline Work-related & 24 & 1,965 & 1,989 & 1.2 \\
\hline Other/unknown & 487 & 22,281 & 22,768 & 2.1 \\
\hline Other private & 826 & 36,485 & 37,311 & 2.2 \\
\hline Traffic-related & 127 & 4,911 & 5,038 & 2.5 \\
\hline Home/garden work & 14 & 267 & 281 & 5.0 \\
\hline Suicide attempt & 26 & 25 & 51 & 51.0 \\
\hline Total & 1,518 & 72,104 & 73,622 & 2.1 \\
\hline \multicolumn{5}{|l|}{ Diagnosis } \\
\hline Concussion & 100 & 56,563 & 56,663 & 0.2 \\
\hline Epidural hematoma & 39 & 1,028 & 1,067 & 3.7 \\
\hline Unspecified brain injury & 149 & 3,301 & 3,450 & 4.3 \\
\hline Diffuse brain injury & 173 & 2,413 & 2,586 & 6.7 \\
\hline Subarachnoid hemorrhage & 155 & 2,137 & 2,292 & 6.8 \\
\hline Focal brain injury & 124 & 1,223 & 1,347 & 9.2 \\
\hline Subdural hematoma & 596 & 4,537 & 5,133 & 11.6 \\
\hline Other brain injury & 107 & 723 & 830 & 12.9 \\
\hline Brain injury with prolonged coma & 9 & 48 & 57 & 15.8 \\
\hline Brain edema & 66 & 131 & 197 & 33.5 \\
\hline Total & 1,518 & 72,104 & 73,622 & 2.1 \\
\hline
\end{tabular}


Table 5 Incidences, case fatality rates, and mortality rates by population of residency and by availability of traumatic brain injury hospital in area of residency

$\mathrm{TBI}=$ traumatic brain injury

\begin{tabular}{|c|c|c|c|c|c|c|}
\hline $\begin{array}{l}\text { Population in } \\
\text { village/town/city of } \\
\text { residence }\end{array}$ & 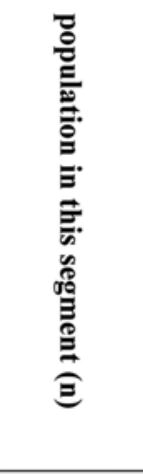 & 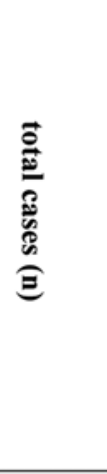 & 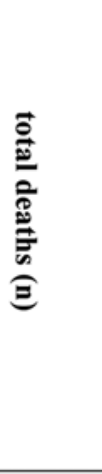 & 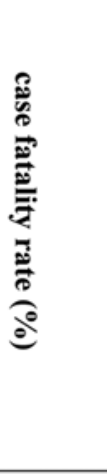 & 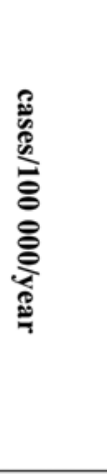 & 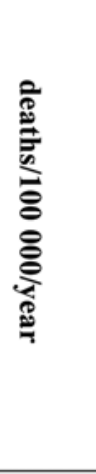 \\
\hline$<1000$ & 388585 & 3772 & 162 & 4.3 & 323.6 & 13.9 \\
\hline $1000-1999$ & 1227949 & 9686 & 411 & 4.2 & 262.9 & 11.2 \\
\hline 2000-2999 & 967373 & 8482 & 307 & 3.6 & 292.3 & 10.6 \\
\hline $3000-3999$ & 616483 & 5398 & 191 & 3.5 & 291.9 & 10.3 \\
\hline $4000-5999$ & 723531 & 6357 & 240 & 3.8 & 292.9 & 11.1 \\
\hline $.000-9999$ & 720225 & 6912 & 250 & 3.6 & 319.9 & 11.6 \\
\hline $10000-29999$ & 919427 & 7914 & 276 & 3.5 & 286.9 & 10.0 \\
\hline $30000-99999$ & 421934 & 3808 & 115 & 3.0 & 300.8 & 9.1 \\
\hline $100000-299999$ & 726275 & 6295 & 192 & 3.1 & 288.9 & 8.8 \\
\hline$>300000$ (Vienna) & 1731236 & 16120 & 496 & 3.1 & 310.4 & 9.6 \\
\hline total & 8443018 & 74744 & 2640 & 3.5 & 295.1 & 10.4 \\
\hline p-value & & & & 0.017 & 0.342 & 0.022 \\
\hline \multicolumn{7}{|l|}{ TBI hospital in area } \\
\hline no & 4805593 & 40518 & 1577 & 3.9 & 281.0 & 10.9 \\
\hline yes & 3637425 & 34226 & 1063 & 3.1 & 313.6 & 9.7 \\
\hline total & 8443018 & 74744 & 2640 & 3.5 & 295.1 & 10.4 \\
\hline p-value & & & & 0.07 & 0.182 & 0.406 \\
\hline
\end{tabular}

The overall incidence of 303/100,000/year found in our study is lower than the incidences of 337 [7] and of $332 / 100,000 /$ year [8] calculated for German regions, and of354/100,000/yeargivenfor NorthernSweden [9].Alower incidence of 235/100,000/year was reported by Tagliaferri et al. [2]; however, the incidences given in the reviewed studies were 100-546/100,000/year. Higher rates were reported for the British region of Exeter (453/100,000/ year [10]), for the United States (538/100,000/year [11]), and for New Zealand (790/100,000/year [12]). This latter study also included self-referred cases who were considered to have had TBI if they "had seen stars" or "were dazed" or "confused" after a head injury. The incidence was calculated from 1,369 cases, and only 71 cases $(5.2 \%)$ had moderate-to-severe TBI. In most other studies, moderate and severe cases contributed to approximately $15 \%$; thus, the New Zealand study may have overestimated the number of cases with mild TBI. Alternatively, all other studies done so far may have underestimated the number of cases with mild TBI. The overall MR $(11 / 100,000 /$ year) and CFR (3.6\%) are lower than those reported by Tagliaferri et al. (15/100,000/year and $11 \%$, respectively [2]). Again, the rates given in the reviewed studies were $5.2-24.4 / 100,000 /$ year and $1-25 \%$, respectively. An MR of 17.5/100,00/year was calculated for the United States [11].

The ratio between male and female cases was 1.4:1 for all, and was 2.2:1 for fatal cases. Comparable male-tofemale ratios (all cases) were reported for Sweden (1.2:1 [11]) and for the United States (1.5:1 [11]). For severe and fatal cases, male:female rates of 3:1 (France [13]) and 3.6:1 (United States [6]) have been published. The difference in the male-to-female ratios between all cases and severe cases is due to the higher CFRs in males, which was also observed in our study.

Regarding age, our data are in accordance with some previous studies $[11,14]$ : we found a peak in teens and young adults, and a second peak in geriatric patients. Studies from New Zealand, however, reported a first peak in children $<5$ years of age, and a second peak in teens and young adults [12, 15]; almost $70 \%$ were observed in cases aged $<35$ years. In our study, due to the high number of geriatric TBI, cases aged $<35$ years contributed only to $43 \%$ of all cases. A significant increase in the rates of geriatric TBI was documented in studies from the United States [16] and Italy [17].

Austrian hospitals record the activity during which an accident occurred as "cause of injury," and the record- 
able activities have been selected to define which social security institution has to pay for treatment. The activities "school," "work," and "traffic to/from work" are covered by AUVA (see above); all other activities are covered by health insurance. Thus, many possible mechanisms are summarized under "other private" activities. With regard to TBI, most of these cases are falls; however, cases of unintentional hits, of objects falling on patients, and of TBI due to other external forces (explosion, firearm injury) could be summarized under "other private" activities, too. For fatal cases, more detailed descriptions of cause and mechanism of injury are recorded on the death certificates. Even with these limitations in mind, the extremely high rate of falls found in our study (up to $80 \%$ of all hospitals discharges, $43 \%$ of all fatal cases) as well as the extremely low rate of traffic-related TBI ( $7 \%$ of all hospital discharges, $17 \%$ of all fatal cases) is remarkable. In most previous studies, TBI was caused by traffic-related events more frequently than by falls [2]. Studies from Norway [18], with $62 \%$ falls and $21 \%$ traffic; Sweden [14], with $58 \%$ falls and $16 \%$ traffic; and Finland [19], with $61 \%$ falls and $26 \%$ traffic-related injuries, reported rates somehow comparable with those found in Austria. The higher number of falls in our study is most probably due to the large proportions of geriatric ( $25 \%$ of all cases aged $>64$ years) and pediatric cases $(19 \%$ of all cases aged $<15$ years) in our study.

Another remarkable aspect of our study is the high CFR of suicides. Suicides were the cause of TBI in $0.7 \%$ of all cases (178/25,456 cases/year), and in $19 \%$ of all fatal cases. Firearms were the most frequently observed mechanism of suicide-related TBI (87\%). Only few of the patients made it to a hospital alive; most died at the scene. Half of the patients who were admitted to hospitals died there, including patients who died on the scene (508/533 cases died; CFR: 95\%). A much lower rate of suicides $(0.1 \%)$ was found in a German study [8]. A high proportion of suicides by firearms $(29 \%$ of all fatal TBI cases!) was found in a study from the United States [6].

The rate of TBI due to inter-personal violence was rather low $(1.7 \%)$. Higher rates were published in studies from Scotland (28\% [20]), Sweden (15\% [21]), Germany (14.2\% [8]), and the United States (11\% [22]). This difference might partly be due to under-reporting, as it is not uncommon that beaten women report "fall" rather than "having been hit" as cause of accident to avoid further problems with their violent partners. The difference might also partly be due to the fact that the age-group most at risk (i.e., young males aged 15-24 years) represents $<6 \%$ of the Austrian population.

Limitations of this study include the following: the data regarding outpatients and re-admissions have been estimated from the documented numbers of cases available from AUVA hospitals. This sample ( $n=7,645$ cases) represents $10.4 \%$ of all hospital discharges $(n=73,622$ cases). Discharge and re-admission strategies might be different at other trauma departments, and the actual rates of outpatients and re-admissions may be incorrect. The same is true for the estimated number of patients with TBI who have been coded as "multiple trauma."
However, given the low numbers of re-admissions, outpatients, and patients with multiple trauma plus TBI, any errors are unlikely to significantly change calculated incidence, CFR, and MR. We are confident that this study included all patients with relevant TBI over a period of 3 years. Cases with mild TBI who did not need medical attention are not included in this study, but these cases are unlikely to be of any relevance.

\section{Conclusions}

Our study showed that incidence, CFR, and MR of TBI in Austria are comparable with those from other European countries. We found a high rate of geriatric TBI. The most common mechanism was falls; traffic accidents accounted for only $7 \%$ of the cases. CFRs were higher in patients from less populated areas, and MRs were lower in cases who lived closer to hospitals that admitted TBI. The Austrian system of reporting cause of accident for hospital admissions should be changed to describe the actual mechanism instead of the activity during which the accident occurred, and should include severity of TBI. The high rate of geriatric TBI warrants better prevention of falls in this age-group.

\section{Acknowledgments}

We are very grateful to the following experts: Dr. Erika Baldaszti (Statistik Austria) who provided data on hospital discharges of patients with TBI and data on deaths due to external causes (which included all deaths due to TBI), Dr. Michael Szivak [Austrian Worker's Compensation Board (AUVA)] who provided data on hospitals discharges of patients with TBI and on outpatients with TBI treated in Austrian Trauma hospitals, and Mag. Robert Sinz (Main Association of the Austrian Social Security Institutions) who provided data on hospitals that admitted patients with TBI.

\section{Funding}

This work was supported by a grant from the Austrian Worker's Compensation Board (AUVA; FK 09/13). The International Neurotrauma Research Organization (INRO) is supported by an annual grant from Mrs. Ala Auersperg-Isham and Mr. Ralph Isham, and by small donations from various sources.

\section{Conflicts of interest}

There are no conflicts of interest

\section{Open Access}

This article is distributed under the terms of the Creative Commons Attribution Noncommercial License which permits any noncommercial use, distribution, and reproduction in any medium, provided the original author(s) and the source are credited. 


\section{References}

1. Hyder AA, Wunderlich CA, Puvanachandra P, Gururaj G, Kobusingye OC. The impact of traumatic brain injuries: a global perspective. NeuroRehabilitation. 2007;22(5):341-53.

2. Tagliaferri F, Compagnone C, Korsic M, Servadei F, Kraus J. A systematic review of brain injury epidemiology in Europe. Acta Neurochir (Wien). 2006 Mar;148(3):255-68; discussion 68.

3. Coburn K. Traumatic brain injury: the silent epidemic. AACN Clin Issues Crit Care Nurs. 1992 Feb;3(1):9-18.

4. Coronado VG, Xu L, Basavaraju SV, McGuire LC, Wald MM, Faul MD, et al. Surveillance for traumatic brain injuryrelated deaths-United States, 1997-2007. MMWR Surveill Summ. 2011 May 6;60(5):1-32.

5. Rosso A, Brazinova A, Janciak I, Wilbacher I, Rusnak M, Mauritz W. Severe traumatic brain injury in Austria II: epidemiology of hospital admissions. Wien Klin Wochenschr. 2007 Feb;119(1-2):29-34.

6. Adekoya N, Majumder R. Fatal traumatic brain injury, West Virginia, 1989-1998. Public Health Rep. 2004 Sep-Oct;119(5):486-92.

7. Steudel WI, Cortbus F, Schwerdtfeger K. Epidemiology and prevention of fatal head injuries in Germany-trends and the impact of the reunification. Acta Neurochir (Wien). 2005 Mar;147(3):231-42; discussion 42.

8. Rickels E, von Wild K, Wenzlaff P. Head injury in Germany: a population-based prospective study on epidemiology, causes, treatment and outcome of all degrees of head-injury severity in two distinct areas. Brain Inj. 2010;24(12):1491-504.

9. Styrke J, Stalnacke BM, Sojka P, Bjornstig U. Traumatic brain injuries in a well-defined population: epidemiological aspects and severity. J Neurotrauma. 2007 Sep;24(9):1425-36.

10. Yates PJ, Williams WH, Harris A, Round A, Jenkins R. An epidemiological study of head injuries in a UK population attending an emergency department. J Neurol Neurosurg Psychiatry. 2006 May;77(5):699-701.

11. Rutland-Brown W, Langlois JA, Thomas KE, Xi YL. Incidence of traumatic brain injury in the United States, 2003. J Head Trauma Rehabil. 2006 Nov-Dec;21(6):544-8.
12. Feigin VL, Theadom A, Barker-Collo S, Starkey NJ, McPherson $\mathrm{K}$, Kahan M, et al. Incidence of traumatic brain injury in New Zealand: a population-based study. Lancet Neurol. 2013 Jan;12(1):53-64.

13. Masson F, Thicoipe M, Mokni T, Aye P, Erny P, Dabadie P. Epidemiology of traumatic comas: a prospective population-based study. Brain Inj. 2003 Apr;17(4):279-93.

14. Andersson EH, Bjorklund R, Emanuelson I, Stalhammar D. Epidemiology of traumatic brain injury: a population based study in western Sweden. Acta Neurol Scand. 2003 Apr;107(4):256-9.

15. Barker-Collo SL, Wilde NJ, Feigin VL. Trends in head injury incidence in New Zealand: a hospital-based study from $1997 / 1998$ to $2003 / 2004$. Neuroepidemiology. 2009;32(1):32-9.

16. Ramanathan DM, McWilliams N, Schatz P, Hillary FG. Epidemiological shifts in elderly traumatic brain injury: 18-year trends in Pennsylvania. J Neurotrauma. 2012 May 1;29(7):1371-8.

17. Stocchetti N, Paterno R, Citerio G, Beretta L, Colombo A. Traumatic brain injury in an aging population. J Neurotrauma. 2012 Apr 10;29(6):1119-25.

18. Ingebrigtsen $T$, Mortensen $K$, Romner $B$. The epidemiology of hospital-referred head injury in northern Norway. Neuroepidemiology. 1998;17(3):139-46.

19. Alaranta H, Koskinen S, Leppanen L, Palomaki H. Nationwide epidemiology of hospitalized patients with first-time traumatic brain injury with special reference to prevention. Wien Med Wochenschr. 2000;150(22):444-8.

20. Thornhill S, Teasdale GM, Murray GD, McEwen J, Roy CW, Penny KI. Disability in young people and adults one year after head injury: prospective cohort study. BMJ. 2000 Jun 17;320(7250):1631-5.

21. Kleiven S, Peloso PM, von Holst $\mathrm{H}$. The epidemiology of head injuries in Sweden from 1987 to 2000. Inj Control Saf Promot. 2003 Sep;10(3):173-80.

22. Langlois JA, Rutland-Brown W, Wald MM. The epidemiology and impact of traumatic brain injury: a brief overview. J Head Trauma Rehabil. 2006 Sep-Oct;21(5):375-8. 